\title{
Early prognostic factors in distal radius fractures in a younger than osteoporotic age group: a multivariate analysis of trauma radiographs
}

\author{
Annechien Beumer ${ }^{1 *}$, Catharina Adlercreutz ${ }^{2}$ and Tommy R Lindau ${ }^{3}$
}

\begin{abstract}
Background: Treatment of distal radius fractures in patients of a younger than osteoporotic age is complex, because they often are the result of a high-energy trauma and have intra-articular fractures and associated injuries. As yet no fracture classification exists that predicts outcome. Our aim was to find the earliest possible prognostic factor by testing which radiological parameter on the trauma radiograph would have the greatest impact on clinical outcome in a younger than osteoporotic age group.

Methods: We assessed 66 patients (34 F) with unilateral fractures of the distal radius from a non-Osteoporotic age group. The median age was 42 years, $\left(10^{\text {th }}-90^{\text {th }}\right.$ percentile $\left.20-54\right)$. Pre-reduction antero-posterior and lateral wrist radiographs were obtained and fracture pattern, radiocarpal joint surface tilt, radial length, radial inclination and ulnar variance were measured. Clinical outcome was assessed with the subjective part as well as the complete modified Gartland and Werley score. Multivariate analysis of those parameters was performed to assess which radiological parameter would best predict outcome.

Results: It was found that post-traumatic ulna $+(>2 \mathrm{~mm})$ was the single factor that significantly correlated with a bad outcome. An intra-articular fracture pattern may also be a strong marker; however this was not statistically significant (RR 95\% conf interval 0.94 - 20.59).

Conclusions: The present study showed that post-traumatic ulna + is the most important factor in predicting bad outcome in non-osteoporotic patients, but that especially intra-articular fractures and to a lesser extent dorsal tilt may be of importance too.
\end{abstract}

Keywords: Ddistal radius fracture, Prognostic factor, Radiology, Outcome

\section{Background}

It is known that distal radius fractures in patients of the non-osteoporotic age usually result from high energy trauma and often have intra-articular involvement $[1,2]$. Furthermore, they are associated with a higher incidence of cartilage, inter-carpal ligament and TFCC lesions $[3,4]$. These fractures are correlated with a worse outcome when instability of the distal radioulnar joint is present [5]. This instability does not correlate with radiographic features at the time of the trauma or at follow-up but to the presence of arthroscopically diagnosed peripheral TFCC-tears [6,7].

\footnotetext{
* Correspondence: achbeumer@hotmail.com

${ }^{1}$ Department of Orthopaedics, Amphia Hospital, Breda, The Netherlands Full list of author information is available at the end of the article
}

In order to predict, and thereby hopefully prevent, a bad outcome in non-osteoporotic fractures it is important to find the earliest prognostic markers for general bad outcome. These are patient characteristics and radiographic measurements on the traumaradiograph. The aim of this study was to assess the most objective parameters on the initial radiograph; these are i.e. radiocarpal joint surface tilt, radial length, radial inclination, ulnar variance. Furthermore we assessed more subjective radiologic parameters such as comminution as described in the subclasses of the AO-classification [8] and fractures through the ulnar styloid or the distal radio-ulnar or radiocarpal joint surfaces. In order to correlate these findings with functional outcome these findings were correlated with objective and subjective
Ciomed Central

(C) 2013 Beumer et al.; licensee BioMed Central Ltd. This is an Open Access article distributed under the terms of the Creative Commons Attribution License (http://creativecommons.org/licenses/by/2.0), which permits unrestricted use, distribution, and reproduction in any medium, provided the original work is properly cited. 
clinical outcome as assessed with the modified Gartland and Werley score $[9,10]$ at 2 years (middle long) followup of distal radius fractures in a younger than osteoporotic age group. We correlated the radiological findings with both the subjective part as well as the complete modified Gartland and Werley score to assess whether the subjective part alone could be used as a patient reported outcome measure.

\section{Methods}

During a consecutive year, all patients with distal radial fractures from a non-osteoporotic age group (men 2059, women 20-49 years of age), without risk factors for osteoporosis, such as alcoholism, steroid use or early menopause, were seen by the same team of orthopaedic surgeons at the department of orthopaedics of Lund University Hospital, Sweden. Pre-reduction AnteroPosterior (AP) and lateral wrist radiographs were obtained and radiocarpal joint surface tilt, radial length, radial inclination and ulnar variance were measured (Figure 1). The normal value for radiocarpal joint surface tilt (dorsal angulation) is from $0^{\circ}$ to palmer $22^{\circ}$ [11-13], radial inclination (or angulation) ranges from $19^{\circ}$ to $29^{\circ}$ $[12,14]$, radial length normally is between 8 and17 $[13,15]$, and ulnar variance ranges from minus 4 to plus $2 \mathrm{~mm}[14,16]$. Therefore palmar angulation exceeding $22^{\circ}$ volar tilt or dorsal angulation tilted dorsally of the zero level, radial length less than $8 \mathrm{~mm}$ and radial

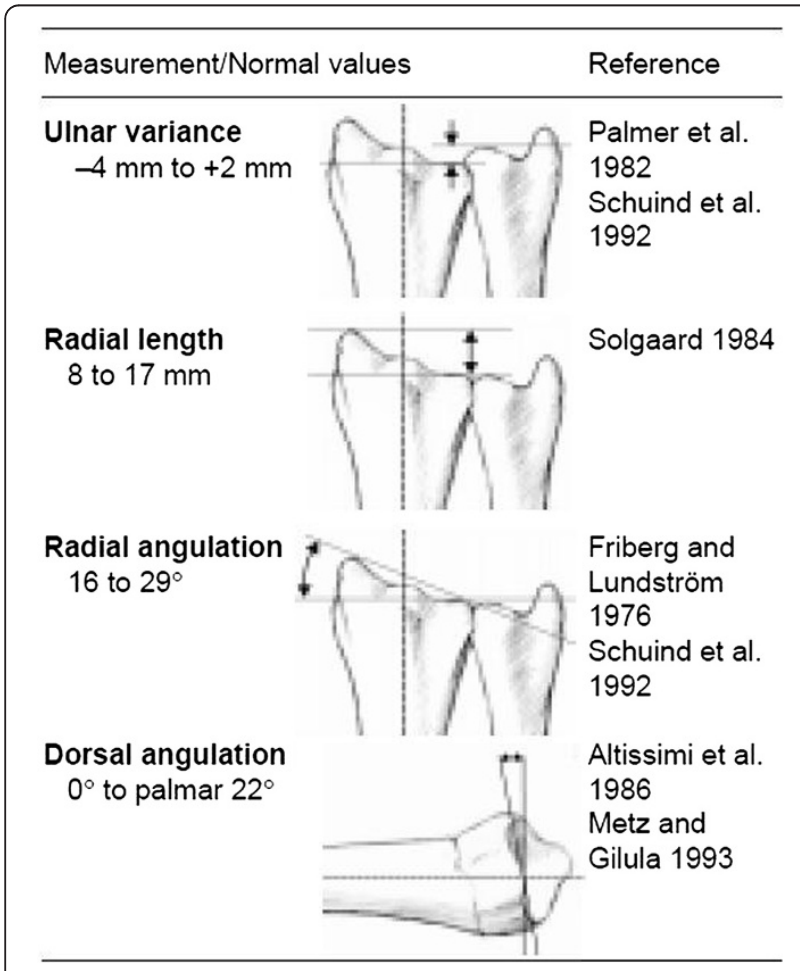

Figure 1 Radiographic Parameters. inclination less than $19^{\circ}$ or exceeding $29^{\circ}$ as well as ulnar variance exceeding plus $2 \mathrm{~mm}$ (Ulna+) were considered pathological. Furthermore, assessment was done whether comminution [8], or fractures through the ulnar styloid or the distal radio-ulnar or radiocarpal joint surfaces were present. Those fracture criteria that could not be quantified in degrees of dislocation but merely as present/absent or more or less severe were considered 'subjective radiologic criteria'. A logistic regression analysis of the above mentioned parameters on the initial trauma radiographs was performed to assess which parameters would have the greatest impact on clinical outcome as assessed with the subjective part of the modified Gartland and Werley score as well as the complete modified Gartland and Werley score $([9,10]$, Appendix 1). This study was conducted in accordance with the guidelines published by the Swedish Research Council and the International Committee of Medical Journal Editors and supported by the institutional review board of Lund University Hospital. Written informed consent was obtained from the patient for publication of this report and any accompanying images.

\section{Results}

92 patients with 95 distal radial fractures were included. Thirteen patients were lost to follow-up, 10 patients did not have trauma radiographs because of immediate reduction in the emergency department making it impossible to include them in this study and 3 had to be excluded because of bilateral fractures and/or mental disability. This left 66 patients (34 F) with unilateral fractures of the distal radius. The median age was 42 years, $\left(10^{\text {th }}-90^{\text {th }}\right.$ percentile 20 -54). Fifty-seven fractures were treated with plaster, 25 of those had needed closed reduction. Nine fractures were treated surgically. Median time of immobilization was 4 weeks (10-90 percentile 3-6 weeks). The median followup was 27 (10-90 percentile 16-36) months. Posttraumatic ulna $+(>2 \mathrm{~mm})$ was the only statistically significant of all factors predicting outcome in both subjective (subjective part of Gartland and Werley Score) and objective-subjective (i.e. complete Gartland and Werley Score) clinical assessment according to the logistic regression analysis (Table 1). A fracture through the radiocarpal joint was a statistically significant factor when only subjective radiologic parameters (comminution, fractures through radiocarpal or radioulnar joint surface or fracture of the ulnar styloid) were correlated with objectivesubjective assessment (complete Gartland Werley score), but not when the entire group of radiologic parameters was correlated with objective-subjective assessment (Tables 2 and 3).

\section{Discussion}

Our aim was to study the earliest possible prognostic radiologic factor regarding outcome for distal radius 
Table 1 Objective and subjective radiologic parameters correlated with objective-subjective assessment (complete Gartland Werley score)

\begin{tabular}{llll}
\hline Factor & Odds ratio $^{\mathbf{1}}$ & $\mathbf{9 5 \%}$ & Conf $^{\text {Int }} \mathbf{p}$-value \\
\hline Ulna + & 2.53 & $1.18-5.41$ & 0.017 \\
Radiocarpal \# & 4.41 & $0.94-20.59$ & 0.059 \\
Dorsal Tilt & 1.06 & $0.99-1.14$ & 0.073 \\
Radial Length & 0.97 & $0.43-2.17$ & 0.937 \\
Radial Inclination & 1.13 & $0.73-1.73$ & 0.588 \\
Proc Styl Ulna \# & 2.02 & $0.37-11.06$ & 0.416 \\
DRUJ \# & 4.09 & $0.65-25.73$ & 0.134 \\
Comminution & 2.57 & $0.30-21.50$ & 0.384 \\
\hline
\end{tabular}

${ }^{1}$. Adjusted for differences in age and sex

+ Positive ulnar variance.

\# Fracture.

fractures in non-osteoporotic patients. Therefore we studied radiological parameters on the initial traumaradiographs. Our patients were followed for a median follow-up of 27 months. We consider this a relevant follow-up for the purpose of this study as literature shows that improvement after distal radius fracture is mainly in the first year $[17,18]$. We studied the entire group of distal radius fractures and not just those treated in plaster or surgically because we searched for the earliest prognostic factor regardless of treatment. It was found that post-traumatic ulna $+(>2 \mathrm{~mm})$ was the only statistically significant factor that could predict a bad outcome in these non-osteoporotic patients in our setting. This was found both when the subjective part of modified Gartland and Werley score and the complete modified Gartland and Werley score were assessed. When the complete modified Gartland and Werley score was tested we also found dorsal tilt and intra-articular fractures through the radiocarpal joint surface to be factors of importance in the final outcome. These factors didn't come out with statistically significant values, analyzing the confidence intervals, however, suggest them to be of importance (Table 1).

Other parameters that describe fracture dislocation (radial length and radial inclination) as well as comminution,

Table 2 Subjective radiologic parameters correlated with objective-subjective assessment (complete Gartland Werley score)

\begin{tabular}{llll}
\hline Factor & Odds ratio $^{\mathbf{1}}$ & $\mathbf{9 5 \%}$ Conf Int & p-value \\
\hline Radiocarpal \# & 2.57 & $0.84-7.89$ & 0.099 \\
Proc Styl Ulna \# & 2.27 & $0.71-7.19$ & 0.165 \\
DRUJ \# & 2.30 & $0.60-8.83$ & 0.224 \\
Comminution & 0.44 & $0.11-1.72$ & 0.236 \\
\hline
\end{tabular}

${ }^{1}$. Adjusted for differences in age and sex.

+ Positive ulnar variance.

\# Fracture.
Table 3 Objective and subjective radiologic parameters correlated with subjective assessment (subjective part of Gartland Werley score)

\begin{tabular}{llll}
\hline Factor & Odds ratio $^{\mathbf{1}}$ & $\mathbf{9 5 \%}$ & Conf Int p-value \\
\hline Ulna + & 1.05 & $1.01-3.26$ & 0.045 \\
Radiocarpal \# & 1.89 & $0.56-6.37$ & 0.306 \\
Dorsal Tilt & 1.05 & $0.99-1.11$ & 0.134 \\
Radial Length & 1.17 & $0.59-2.30$ & 0.654 \\
Radial Inclination & 0.93 & $0.66-1.33$ & 0.704 \\
Proc Styl Ulna \# & 0.94 & $0.21-4.27$ & 0.938 \\
DRUJ \# & 1.73 & $0.36-8.33$ & 0.493 \\
Comminution & 2.57 & $0.46-20.29$ & 0.250 \\
\hline
\end{tabular}

1 . Adjusted for differences in age and sex.

+ Positive ulnar variance.

\# Fracture.

fracture through the radiocarpal, radioulnar joint surfaces and ulnar styloid did not correlate with a bad clinical outcome after distal radius fractures in this non-osteoporotic age group. This is in agreement with the literature where the commonly used fracture classifications for distal radius fractures have not shown any correlation with clinical outcome [19-21]. This may be because intra-articular fractures are correlated with associated injuries, such as ligamentous injuries leading to intercarpal injuries $[22,23]$ and TFCC tears causing late DRU-joint instability $[2,6,7]$. Consequently, classifications based on these measurable angles and fracture distributions are not of clinical use, which is further supported by the fact that inter,-and intra observer reliability is poor $[24,25]$.

It is know that patients with intra-articular fractures with more than $2 \mathrm{~mm}$ incongruence have been found to get joint degeneration after 6.7 years [26], the same goes for fractures with more than $10^{\circ}$ of dorsal tilt $[27,28]$ and carpal malalignment $[29,30]$. We therefore advocate to rather use these prognostic factors than classifications in the normal clinical management of these fractures. In research studies, however, there may still be a need to consider using classifications. It could be postulated that a fracture classification involving carpal alignment and presence of ligament and TFCC injury might better predict outcome. This would be an interesting topic for further research.

The subjective part and the combined evaluation of the Gartland and Werley score were tested separately to assess if subjective evaluation alone of the patient would give as much information as the combined evaluation, which would allow for longer follow-up with questionnaires only in the future. In this respect we found the same significance regarding the post-traumatic ulna $+(2 \mathrm{~mm})$ to be the only relevant factor suggesting that in the future we may simplify outcome measurements to the subjective part of the Gartland and Werley score (Tables 1 and 3). 
It can be argued that positive ulnar variance on a prereduction radiograph is not only the result of severe compression and dorsal tilting of the distal radius because of the fracture but instead of a pre-existing longer ulna before the injury. The only way to ascertain if positive ulnar variance was present before injury would have been to obtain radiographs of the contra lateral wrist and assess ulna length. We, as well as most emergency units in the world, choose not to do so because this is not, and will not become, common practice in the treatment of this frequent fracture. However, one might consider obtaining radiographs of the other wrist if there is still an ulna + after reduction to a well aligned radius without any signs of shortening, hereby checking whether there has been a positive ulnar variance before the radius fracture. The majority of our patients were treated non-surgically based on the clinical judgment of the surgeon on call, which is in accordance with common practice in the Scandinavian area in the second half of the past decade [31]. It might be postulated that more aggressive treatment, such as (fixed angle) volar plate fixation, might improve the end result in such a group of patients. This does not change the outcome that ulna + is the most important prognostic factor. It may, however, sharpen the indication for the use of the volar plates.

\section{Conclusion}

The present study shows that intra-articular fractures and to a lesser extent dorsal tilt may be of importance, but that post-traumatic ulna + is the most important factor in predicting bad outcome after distal radius fracture in the non-osteoporotic age group (Table 1).

\section{Appendix 1 modified Gartland and Werley score}

(Gartland and Werley 1952, Sarmiento et al. 1975)

Subjective evaluation (range 0 to 6 points)

Excellent -no pain, disability, or limitation of motion 0p

Good -occasional pain, slight limitation of motion, and no disability $2 \mathrm{p}$

Fair -occasional pain, some limitation of motion, feeling of weakness in wrist, no particular disability if careful, and activities slightly restricted $4 \mathrm{p}$

Poor -pain, limitation of motion, disability, and activities more or less markedly restricted $6 \mathrm{p}$

Residual deformity (range 0 to 3 points)

Prominent ulnar styloid $1 \mathrm{p}$

Residual dorsal tilt $2 \mathrm{p}$

Radial deviation of hand 2-3p

Objective evaluation (range 0 to 5 points)

Loss of dorsiflexion $\left(<45^{\circ}\right) 5 \mathrm{p}$

ulnar deviation $\left(<15^{\circ}\right) 3 \mathrm{p}$

supination $\left(<50^{\circ}\right) 2 \mathrm{p}$

pronation $\left(<50^{\circ}\right) 2 \mathrm{p}$

palmarflexion $\left(<30^{\circ}\right) 1 \mathrm{p}$ radial deviation $\left(<15^{\circ}\right) 1 \mathrm{p}$

circumduction $1 \mathrm{p}$

Pain in distal radio ulnar joint $1 \mathrm{p}$

Grip strength $-60 \%$ or less than the opposite side $1 \mathrm{p}$

Complications (range $0-5$ points)

Arthritic change

minimum $1 \mathrm{p}$

minimum with pain $3 p$

moderate $2 \mathrm{p}$

moderate with pain $4 \mathrm{p}$

severe $3 \mathrm{p}$

severe with pain $5 p$

Nerve complications (median) $1-3 p$

Poor fingerfunction due to cast $1-2 \mathrm{p}$

FINAL RESULTS (ranges of points)

Excellent 0-2p

Good 3-8p

Fair 9-20p

Poor $>21 \mathrm{p}$

\section{Competing interests}

The authors declare that they have no competing interests.

\section{Authors' contributions}

$T L$ designed the study, acquired data, analyzed results and revised the manuscript. CA interpreted radiographs, analyzed results and revised the manuscript. $A B$ analyzed results and wrote and revised the manuscript. All authors read and approved the final manuscript.

\section{Author details}

'Department of Orthopaedics, Amphia Hospital, Breda, The Netherlands. 2Department of Radiology Lund, University Hospital, Lund, Sweden.

${ }^{3}$ Pulvertaft Hand Centre, Derby, UK.

Received: 18 September 2012 Accepted: 23 April 2013

Published: 22 May 2013

References

1. Alffram P-A, Bauer GCH. Epidemiology of fractures of the forearm: A Biomechanical investigation of bone strength. J Bone Joint Surg [A] 1962, 44(1):105-114.

2. Lindau TR, Aspenberg P, Adlercreutz C, Jonsson K, Hagberg L: Distal radioulnar joint Instability is an independent worsening factor in distal radial fractures. Clin Orthop Relat Res 2000, 376:229-235.

3. Bombaci $H$, Polat $A$, Deniz G, Akinci $O$ : The value of plain $X$-rays in predicting TFCC injury after distal radial fractures. J Hand Surg Eur 2008, 33(3):322-326.

4. Lindau TR, Arner M, Hagberg L: Intraarticular lesions in distal fractures of the radius in young adults. A descriptive arthroscopic study in 50 patients. A descriptive, arthroscopic study in 50 patients. J Hand Surg [Br] 1997, 22B:638-643.

5. Lindau TR, Aspenberg P, Arner M, Redlundh-Johnell I, Hagberg L: Fractures of the distal forearm in young adults. A population-based epidemiologic description of 341 patients. Acta Orthop Scand 1999, 70:124-128.

6. Geissler WB, Fernandez DL, Lamey DM: Distal radioulnar joint injuries associated with fractures of the distal radius. Clin Orthop Relat Res 1996 (327):135-146.

7. Lindau TR, Adlercreutz C, Aspenberg P: Peripheral tears of the triangular fibrocartilage complex cause distal radioulnar instability after distal radial fractures. J Hand Surg (Am) 2000, 25(3):464-468.

8. Müller ME, Koch P, Schatzker J: In The comprehensive classification of fractures of long bones. Edited by Müller ME. New York: Springer; 1990:106-115.

9. Gartland JJ Jr, Werley CW: Evaluation of healed Colles' fractures. J Bone Joint Surg Am 1951, 33A:895-907. 
10. Sarmiento A, Pratt GW, Berry NC, Sinclair WF: Colles' fractures: functional bracing in supination. J Bone Joint Surg [Am] 1975, 57:311-317.

11. Altisissimi M, Antenucci R, Fiacca C, Mancini GB: Long-term results of conservative treatment of fractures of the distal radius. Clin Orthop Relat Res 1986, 206:202-210

12. Friberg S, Lundström B: Radiographic measurements of the radio-carpal joint in normal adults. Acta Radiol Diag 1976, 17:249-256.

13. Solgaard S: Angle of inclination of the articular surface of the distal radius. Radiologe 1984, 24:346-348.

14. Schuind FA, Linscheid RL, An KN, Chao EYS: A normal data base of posterioranterior roentgenographic measurements of the wrist. J Bone Joint Surg (Am) 1992, 74:1418-1429.

15. Solgaard S: Distal radius fractures. Classification, function and recommendations to treatment, Thesis. Copenhagen University, Denmark; 1992.

16. Palmer AK, Glisson RR, Werner FW: Ulnar variance determination. J Hand Surgery 1982, 7(4):376-379.

17. Lozano-Calderon SA, Souer S, Mudgal C, Jupiter JB, Ring D: Wrist Mobilization Following Volar Plate Fixation of Fractures of the Distal Part of the Radius. J Bone Joint Surg Am 2008, 90:1297-1304.

18. Souer SJ, Ring D, Jupiter JB, Matschke S, Audige L: Comparison of AO Type- $B$ and Type-C Volar Shearing Fractures of the Distal Part of the Radius. J Bone Joint Surg Am 2009, 91:2605-2611.

19. Flinkkilä T, Raatikainen T, Hämäläinen $\mathrm{M}: \mathrm{AO}$ and Frykman's classifications of Colles' fracture. No prognostic value in 652 patients evaluated after 5 years. Acta Octhop Scand 1998, 69:77-81.

20. Gliatis JD, Plessas SJ, Davis TR: Outcome of distal radial fractures in young adults. J Hand Surg [Br] 2000, 25(6):535-543.

21. Konstantinidis L, Helwig P, Strohm PC, Hirschmüller A, Kron P, Südkamp NP: Clinical and radiological outcomes after stabilisation of complex intra-articular fractures of the distal radius with the volar $2.4 \mathrm{~mm} \mathrm{LCP}$. Arch Orthop Trauma Surg 2010, 130(6):751-757.

22. Forward DP, Lindau TR, Melsom DS: Intercarpal ligament injuries associated with fractures of the distal part of the radius. J Bone Joint Surg [A] 2007, 89(11):2334-2340

23. Geissler WB, Freeland AE, Savoie FH, McIntyre LW, Whipple TL: Intracarpal soft-tissue lesions associated with an intra-articular fracture of the distal end of the radius. J Bone Joint Surg Am 1996, 78(3):357-365.

24. Andersen DJ, Blair WF, Steyers CM Jr, Adams BD, El-Khouri GY, Brandser EA: Classification of distal radius fractures: an analysis of interobserver reliability and interobserver reproducibility. J Hand Surg [A] 1996, 21:574-582.

25. Belloti JC, et al: Are distal radius fractures reproducible? Intra and interobserver agreement. Sao Paulo Med J 2008, 126(3):180-185.

26. Knirk JL, Jupiter JB: Intra-articular fractures of the distal end of the radius in young adults. J Bone Joint Surg [Am] 1986, 68(5):647-659.

27. McQueen MM, Caspers J: Colles' fractures: does the anatomical result affect final function? J Bone Joint Surg (B) 1988, 70:649-651.

28. Solgaard S: Function after distal radius fractures. Acta Orthop Scand 1988 59:39-42.

29. McQueen MM, Hadjucka C, Court-Brown CM: Redisplaced unstable fractures of the distal radius: a Prospective randomised comparison of four methods of treatment. J Bone Joint Surg (B) 1996, 78:404-409.

30. Taleisnik J, Watson HK: Midcarpal instability caused by malunited fractures of the distal radius. J Hand Surg 1984, 9A:350-357.

31. Finsen V, Rod O, Rød K, Rajabi B, Alm-Paulsen PS, Russwurm H: The relationship between displacement and clinical outcome after distal radius (Colles') fracture. J Hand Surg Eur Vol 2013, 38(2):116-126.

doi:10.1186/1471-2474-14-170

Cite this article as: Beumer et al.: Early prognostic factors in distal radius fractures in a younger than osteoporotic age group: a multivariate analysis of trauma radiographs. BMC Musculoskeletal Disorders 2013 14:170.

\section{Submit your next manuscript to BioMed Central and take full advantage of:}

- Convenient online submission

- Thorough peer review

- No space constraints or color figure charges

- Immediate publication on acceptance

- Inclusion in PubMed, CAS, Scopus and Google Scholar

- Research which is freely available for redistribution

Submit your manuscript at www.biomedcentral.com/submit 